\title{
Knowledge on Self-Management and Level of Asthma Control among Adult Asthmatic Patients Attending Kalar General Hospital
}

\author{
Nazanin Qudrat Abbas ${ }^{1}$, Muhammad Rashid Amen² \\ ${ }^{1}$ Khanqin General Hospital \\ ${ }^{2}$ Department of Adult Nursing, College of Nursing. University of Sulaimani
}

\section{Article Info}

Received: July, 2019

Revised:August,2019

Accepted:August,2019

\section{Keywords}

Asthma, Self-management, Asthma control, Kalar,

\section{Corresponding Author} sayunaza66@gmail.com

\begin{abstract}
Background: As asthma is a controllable disease, the aim of asthma management is to control the disease and allow patients to have a normal and healthy life. Self-management of asthma is crucial for disease control and has a positive impact on patient quality of life.

Objectives: The main objective of this study was to determine the level of knowledge of self-management and asthma control and find out the relation between them in asthmatic patients

Methods: A quantitative descriptive design was used to recruit a sample of 83 asthmatics patients attending chronic disease department at Kalar general hospital, from November 2018 to June 2019. The study sample was chosen by convenience sample technique. Data were collected through the questionnaire consist of 4 parts; patients' characteristic, patients lifestyle and biomedical characteristic, Knowledge on Asthma Self-Management Questionnaire, and Asthma Control Test. Data were analyzed by (Statistical Package for the Social Sciences, version 24) descriptive and interferential statistics.

Results: The finding revealed that the (12.0\%) of participants had good knowledge and asthma for (13.3\%) well-controlled. Knowledge and control of asthma correlated positively $(\mathrm{p}<0.01)$. Elderly, low educated, housewife and not adhered to medications had poor knowledge. Whereas, asthma control was low among female, low educated, housewife and retied $(\mathrm{p}<0.05)$.

Conclusions: the rate of asthma control was low and the patients had wide gaps in knowledge of important items related to asthma preventive strategies and medication use which are crucial to self- management of the disease. Substantial efforts to upgrade patients' knowledge are urgently needed, through intensive patient education.
\end{abstract}

\section{Introduction}

Asthma is one of the most significant NonCommunicable Diseases (NCDs) that affecting $1-18 \%$ of the population in different countries and is estimated to affect about 339 million people worldwide. It is a cause of substantial burden of disease, including both premature death (kills nearly 1000 people every day) and reduced quality of life, in people of all ages in all parts of the world [1]. Globally, asthma is ranked 16th among the leading causes of years lived with disability and 28th among the leading causes of burden of disease [2].

As asthma is a controllable disease, the aim of asthma management is to control the disease 
and allow patients to have a normal and healthy life. Asthma control "refers to the extent to which the clinical signs and symptoms of asthma have been reduced or removed by treatment" [3]. According to Global Asthma Report (2018), asthma control focuses on two main domains; fist reducing impairment the frequency and intensity of symptoms and functional limitations currently or recently experienced by a patient; secondly reducing risk the likelihood of future asthma attacks, progressive decline in lung function, or medication side effects.[2] Achieving and maintaining asthma control requires providing appropriate medication, addressing environmental factors that cause worsening symptoms, helping patients learn self-management knowledge skills and monitoring over the long term to assess control and adjust therapy accordingly [2,4,5].

Recent studies revealed that asthmatic patients need to receive sufficient knowledge on asthma self-management, which includes information on the disease, use medications correctly, regularly and prevention of asthma exacerbation [6,7]. This might be achieved if patients receive adequate knowledge of asthma, sign, and symptom, risk factors, exacerbation and prevention of asthma[8]. Patients should also understand guidance on how to use medications continue for a considerable period of time, they should know that adhering to the treatment plan is the strongest mainstay of asthma management [1,8].

Nowadays, despite many advances in asthma diagnosis and treatment, the prevalence of controlled asthma is still low worldwide, including in Iraq [9]. It is reported that the level of asthma control among adult is still less than expected, that is, in Baghdad, was (5\%) only [10]. Many related reasons such as (healthsystem; physicians and patients) may be contributed to this low level of asthma control. Besides issues related to the health care system or to physicians and patient-related problems, the patient's low level of knowledge about the disease (particularly knowledge on selfmanagement) is an important factor contributing to the low level of asthma control [10,11].

Knowledge about self-management encourages the individual to successfully manage their chronic condition [4,8]. In many countries, although levels of asthma selfmanagement are low these can be improved by means of education, and supported asthma selfmanagement can lead to improved asthma control, fewer exacerbations/hospital admissions, and improved quality of life [6,12]. However, little is known about the asthma selfmanagement with respect to asthma control, and no study has evaluated asthma knowledge in Kurdish adults. The aim of this study was to assess knowledge on self-management, asthma control levels and the correlation between them in adult patients with asthma.

\section{Patients and Methods:}

A Quantitative-descriptive design, conducted on 83 adult ( $\geq 18$ years) male and female asthmatic patients visiting Kalar general hospital / chronic disease department through, to determine knowledge of asthma self-management and asthma control levels. A non-probability convenience sample technique was used to select sample.

The study approved by ethical committee in faculty of Medical Science / College of Medicine / University of Sulaimani, also it was accepted by the council of the College of Nursing .

The required data was collected by face to face interview and through a questionnaire which includes: patient's socio-demographic data which includes: age, gender, marital status, education, occupation and financial status. Patient's lifestyle and biomedical characteristics which includes: smoking habit, Body Mass Index BMI, medication adherence, duration of 
disease, family history for asthma and other chronic disease.

The data regarding self-management was collected by Asthma Self-Management Questionnaire (ASMQ). The ASMQ is a validated tool used to assess patients' level of knowledge on self-care management among asthmatic patients. It comprises 16 multiple choice questions which measure knowledge of preventive strategies, correct inhaler use, medications, and use of peak flow meters; it requires about $5 \mathrm{~min}$ to complete when selfadministered or 8-10 min when interviewed [12,]. However, because peak flow meters are not in common use in Kurdistan, for this study, the two items related to use of this device (The correct way to use a peak flow meter is to...) and (The benefit of using a peak flow meter every day is...) were removed. Removing of the above items regarding peak flow meters (spirometer) have been done in Saudi [7] and Vietnam [6] , studies previously for the same reason.

The ASMQ scores were calculated as follow: one score was given to each correct response, all the scores were summed to generate the raw score range $0-14$, the raw score was transformed to range from 0 to 100 , with higher scores indicating more knowledge of asthma selfmanagement.

As in previous studies, the knowledge was categorized into the following levels: good knowledge level (ASMQ >75 out of 100), adequate (ASMQ 50-75 out of 100), poor (ASMQ <50 out of 100) $[6,13,14,15]$.

Furthermore, asthma control levels assessed by Asthma Control Test (ACT). This test comprises five questions assessing the frequency of shortness of breath, frequency of asthma nighttime symptoms, degree of functional limitation, frequency of using rescuers, and patient's self-assessment of their level of asthma control. Each item has five response choices (each with a score ranging from 1 to 5). Accordingly, the level of asthma control is as follows: controlled (score 20-25), partially controlled (score 15-19), uncontrolled (score $<15)[12,16]$. The raw score was transformed to range from 0 to 100 , with higher scores indicating more asthma control for the purpose of determining its relationship with patients' characteristics.

The data were analysed with Statistical Package for the Social Sciences (SPSS) version (24.0). Different statistical tests have been used in order to achieve the objectives of the study as following; descriptive statistics were used, starting with exploratory data analysis, frequency and percentage were used to show patients' socio-demographic, biomedical characteristics, levels of knowledge on asthma self-management and levels of asthma control, mean and standard deviation to determine the average of some variable such as age and BMI. Inferential statistical method, chi-square (Fisher's Exact Test) was used to identify the association between Knowledge on asthma selfmanagement levels with levels of asthma control. (p-value $\leq 0.05$ ) considered as significant level.

\section{Results}

Eighty three patients with chronic bronchial asthma recruited to present study which conducted in Garmian region, Kalar general hospital, chronic disease department. The age of almost half (49.4\%) was more 40 than years, most were female $(62.7 \%)$, married $(79.6 \%)$, illiterate $(54.2 \%)$, housewives $(55.4 \%)$ and reported insufficient financially $(54.2 \%)$ as presented in table 1.

Regarding lifestyle and biomedical characteristics; about one-third $(66.3 \%)$ was a non-smoker, either obese $(33.7 \%)$ or overweight $(28.9 \%)$. More than half $(50.6 \%)$ not adhered to medications, had asthma for more than 10 years (60.2\%), had no family history for asthma $(68.7 \%)$ and another chronic disease (56.6\%), as showed in table 2 . 
The proportion of knowledge regarding selfmanagement, for $(62.7 \%)$ of asthmatic patients was poor, whereas, the proportion of good knowledge was $(12.0 \%)$ only, while the percentage of adequate knowledge was $(25.3 \%)$, as illustrated in figure 1. The level of asthma control was uncontrolled for more than half $(50.6 \%)$ of participants; for about one-third (36.1\%) of them was partially controlled, while the proportion of controlled asthma was low (13.3\%) only, figure 2 .

The most important finding of the current study, was the association between Asthma selfmanagement knowledge and levels of asthma control, which revealed a strong positive correlation, the proportion of patients with good knowledge levels, associated with better asthma control levels, and vice versa the difference was significant statistically, $(\mathrm{p}<0.01)$ as showed in table 3.

\section{Discussion}

To assess the level of knowledge on selfmanagement, levels of disease control and to find out the relation between them, present descriptive study conducted on 83 asthmatic patients attending chronic disease department at Kalar general hospital.

One of the main findings of this study revealed that the level of knowledge on asthma self-management was low, there was a big gap regarding knowledge on disease characteristics, preventions, medications and proper use of an inhaler. ASMQ score was (41.6 out of 100); nearly two-thirds $(62.7 \%)$ had poor knowledge. Few of asthmatic patients (12.0\%) answered more than $75 \%$ questions correctly, which considered good knowledge level.

The above result is inline and comparable to previous studies those used the same study format and questionnaire. Nguyen et al, (2018) reported that the score of ASMQ as 30 out of 100 , they found only $0.3 \%$ of adults had good knowledge, $16.2 \%$ had adequate knowledge, and
83.5\% had poor knowledge regarding selfmanagement among Vietnam asthmatic patients [6]. Furthermore, Elbur et al (2017) reported that the mean raw score of ASMQ in their study conducted in regional country, Saudi Arabia as $3.5 / 14$ which equal to $(25 / 100)$, the mentioned authors found that only $4 \%$ of participants had $>50 \%$ correct answers, whereas it was $16.5 \%$ of participants in this study knowledgeable about their condition, and stated that the patients responses to the items of ASMQ revealed wide gaps in knowledge of asthmatic patients about the disease[7]. Similarly, insufficient knowledge levels were demonstrated by Merghani et al in Sudan[17], and by Borges et al, in Brazil [18].

Many factors may contribute to the poor level of asthma knowledge. First, communication with the physician is the main source of education about asthma, although there are other ways to get information (e.g., nurses, pharmacy, mass, and social media, relative, and so on), these are very limited in some areas, especially suburban or rural. Second, this study was conducted in Kalar City, general hospital, which may patients receive fewer advises regarding patient education; however, many participants came from rural where they probably have fewer opportunities. In addition, the physicians working in a government general hospital are often overloaded, implying that the time available for each patient is limited. Finally, the patient's opportunity to receive an educational program is very low if not absent in such a kind of hospital, because general hospital dealing with the different cases is not like specialty centers.

The ability of the patients to control disease was another main objective of the present study, our finding indicated that the level of asthma control very low; asthma was uncontrolled in more than half of the participants. In almost onethird, asthma partially controlled, the proportion of controlled asthma was (13.3\%) only. 
Regarding asthma control in previous study, according to the obtained scores in Elbur et al (2017) study, the patients with uncontrolled disease were $(42.9 \%)$, while $(33.2 \%)$ were classified with partially control asthma and (23.9\%) with controlled disease[7]. Furthermore, Nguyen et al (2018) found more than half of asthmatic patients either uncontrolled $(33.2 \%)$ or partially controlled (26.4\%)[6].

Asthma control is not difficult to reach target and can be achieved through the design and implementation of a tailored treatment plan that considered the complexity of multiple interrelated factors needed to attain this goal $[19,20]$. One of the few studies assessed asthma control in Africa, reported a high proportion of patients had inadequately controlled asthma and the factors associated with it were female sex and obesity [21].

In the present study, a strong positive correlation was found between asthma selfmanagement knowledge level and asthma control level. The higher the level of knowledge (good), the better the control level (controlled) and, conversely, (p: 0.0001), as presented in table 3. This relationship between asthma knowledge and asthma control was found in previous studies, Nguyen et al (2018) the higher the level of control (controlled), the better the ASMQ score or patients with a better knowledge of asthma self-management (ASMQ score $\geq 50$ ) had better asthma control based on the ACT score[6].

In addition, the Turkish study found that older patients with asthma had limited asthma self-management knowledge and worse asthma control (52\%) uncontrolled, and showed a strong relationship between knowledge of selfmanagement and asthma control levels [22].

\section{Conclusion}

Depending on finding this study identified very wide gaps in patients' knowledge regarding asthma self-management, the level of asthma control was low, and the level of asthma selfmanagement knowledge had a strong impact on the level of asthma control; the more knowledgeable patient had better asthma control, $(\mathrm{p}<0.0001)$.

\section{Recommendations}

The patient's low level of knowledge on the disease particularly knowledge on selfmanagement is an important factor contributing to the low level of asthma control. Therefore, the focus on knowledge regarding disease, medication, and prevention, should be a scientific base for every educational session to improve the level of asthma control. Applying an individual care plan for each asthmatic patient is necessary.

\section{References:}

1.GINA. A Pocket Guide for Health Professionals. Retrieved August 6, 2019, from Global Initiative for Asthma (2019, June 1) [online] at: www.ginasthma.org.

2.GAN. The Global Asthma Report. Retrieved July 5, 2019, from Global Asthma Network 2018 [online] at: www.globalasthmanetwork.org.

3.Taylor DR, Bateman ED, Boulet LP, Boushey HA, Busse WW, Casale TB, Chanez P, Enright PL, Gibson PG, de Jongste JC, Kerstjens HA, Lazarus SC, Levy ML, O'Byrne PM, Partridge MR, Pavord ID, Sears MR, Sterk PJ, Stoloff SW, Szefler SJ, Sullivan SD, Thomas MD, Wenzel SE, Reddel HK. A new perspective on concepts of asthma severity and control. European Respiratory Journal.2008;32:545-54. doi: 10.1183/09031936.00155307.

4.CDC. Asthma surveillance Data. Retrieved June 14, 2019, from Center of Disease Control. Asthma Data and Survillance (2018 a, March):[online] at: http://www.cdc.gov/asthma/asthmadata.htm.

5.Al-Moamary, M., Alhaider, S., Alangari, A., Al Ghobain, M., Zeitouni, M., Idrees, M., ... Al-Hajjaj, M. The Saudi Initiative for Asthma - Update: Guidelines for the diagnosis and management of asthma in adults and children. Annals of Thoracic 
Medicine. 2019; 14(1),

https://doi.org/10.4103/atm.atm_327_18 .

6.Nguyen, V., Huynh, T., and Chavannes, N., Knowledge on self-management and levels of asthma control among adult patients in Ho Chi Minh City, Vietnam, International Journal of General Medicine. 2018; 11;81-89.

7. Elbur, A. \& Alharthi, B.J, \& Alharthi.S.A, Selfmanagement and control of asthma among adult patients in King Faisal Medical Complex Taif, KSA. International Journal of Research in Pharmacy and Science. 2017; 7. 24 - 29.

8.WHO. Asthma. Retrieved July 25, 2019, from World Health Organization .(2017, August 31), [online] at: https://www.who.int/news-room/factsheets/detail/asthma.

9.Sultan, K. M., Jamer, A. H., \& Obaidy, M. W. A. Comparison of Asthma Control Test (ACT) with (GINA) guidelines in the Assessment of Asthma Control and determine if can use Asthmda Control Test ACT as alternative to Gina guidelines in control asthma. Journal of the Faculty of Medicine. 2016; 58(1), 1-7.

10.Aliwie A. and Ahmed S., Assessment the Severity of Asthma on Patients in Specialist Respiratory Center in Baghdad City, Kufa Journal For Nursing Sciences. 2016:6(1).

11.Roberts E, Velsor-Friedrich B, Keough V. Implementation of an Asthma Self-Management Education Guideline in the Emergency Department. Advanced emergency nursing journal. 2018; 40(1):45-58.

12.Mancuso CA, Sayles W, Allegrante JP. Knowledge, attitude, and selfefficacy in Asthma selfmanagement and quality of life. J Asthma.2010;47(8):883-888.

13.Malarvizhi M, Hariprasad B, Bhavani M. Determine the level of knowledge and practice among asthmatic patients attending chest opd at selected hospitals, Chennai. International Journal of Advanced Information and communication Technology. 2014;1(3).32.

14.Sharifi L, Pourpak Z, Heidarnazhad H, Bokaie S, Moin M. Asthma knowledge, attitude, and selfefficacy in Iranian asthmatic 5patients. Arch Iran Med. 2011;14():315-320.

15.Madhushani HPD, Subasinghe HWAS. Knowledge attitudes and practices of asthma; Does it associate with demographic factors of adult patients? Asian Pac J Health Sci.2016;3(4S):94-99.

16. Schatz M, Sorkness CA, Li JT, et al. Asthma Control Test: reliability, validity, and responsiveness in patients not previously followed by asthma specialists. J Allergy Clin Immunol. 2006;117(3):549-556.

17.Merghani TH, Toum IM, Zaki AM, Ahmed AM., Knowledge, attitude and behaviour of asthmatic patients regarding asthma in urban areas in Khartoum State, Sudan. Khartoum Med J.2011;4(1):524-527.

18. Borges MC, Ferraz É, Pontes SM, et al. Development and validation of an asthma knowledge questionnaire for use in Brazil. J Bras Pneumol. 2010;36(1):8-13.

19. Rodrigues CD, Pereira RP, DalcinPde T., Effects of an outpatient education program in patients with uncontrolled asthma. J Bras Pneumol.2013; 39: 272-9.

20.Farrell, M., Smeltzer, S. C., \& Bare, B. G., Smeltzer \& Bare's textbook of medical-surgical nursing ,4th ed. North Ryde, Nsw: Lippincott Williams \& Wilkins.2017; 611-615.

21. Hugo, M. N., Walter, P. Y., Maïmouna, M., Malea, N. M., Ubald, O., Adeline, Wand Christopher, K. , Assessment of asthma control using asthma control test in chest clinics in Cameroon: a crosssectional study. The Pan African medical journal, 2016;23, 70. doi:10.11604/pamj.70.8434.

22.Ozturk B, Ozyigit Pur L, Kostek O, and. Keskin H., Association between asthma self-management knowledge and asthma control in the elderly, Annals of Allergy Asthma Immunol. 2015;114; 480-484. 
Table (1) Distribution of participants' socio-demographic characteristics

\begin{tabular}{|c|c|c|c|}
\hline \multicolumn{2}{|c|}{ Socio-Demographic Characteristics } & \multirow{2}{*}{$\begin{array}{l}\text { Frequency } \\
10\end{array}$} & \multirow{2}{*}{$\begin{array}{l}\text { Percentage } \\
12.0\end{array}$} \\
\hline Age & 20-39 Years & & \\
\hline & 40-59 Years & 41 & 49.4 \\
\hline & $\geq 60$ Years & 32 & 38.6 \\
\hline & Mean $\pm \mathrm{Sd}$ & $55.8 \pm 14.4$ & \\
\hline \multirow[t]{2}{*}{ Gender } & Female & 52 & 62.7 \\
\hline & Male & 31 & 37.3 \\
\hline \multirow[t]{3}{*}{ Marital Status } & Single & 10 & 12.0 \\
\hline & Married & 66 & 79.6 \\
\hline & Widow / Separated & 7 & 8.4 \\
\hline \multirow[t]{4}{*}{ Educational Level } & Illiterate & 45 & 54.2 \\
\hline & Primary School & 21 & 25.3 \\
\hline & Secondary School & 12 & 14.5 \\
\hline & Institute/College & 5 & 6.0 \\
\hline \multirow[t]{4}{*}{ Occupation } & Government Employee & 9 & 10.8 \\
\hline & Self-Employee & 13 & 15.7 \\
\hline & Housewife & 46 & 55.4 \\
\hline & Retired & 15 & 18.1 \\
\hline \multirow[t]{3}{*}{ Financial Status } & Sufficient & 11 & 13.3 \\
\hline & Barely Sufficient & 27 & 32.5 \\
\hline & Insufficient & 45 & 54.2 \\
\hline Total & & 83 & 100 \\
\hline
\end{tabular}


Table (2) Distribution of participants' lifestyle and biomedical characteristics

\begin{tabular}{l|lll}
\multicolumn{1}{l}{ Patients' Lifestyle And Biomedical Characteristics } & Frequency & Percentage \\
\hline Smoking & Non Smoker & 55 & 66.3 \\
& Current Smoker & 2 & 2.4 \\
Body Mass Index (Bmi) & X Smoker & 26 & 31.3 \\
& Normal & 31 & 37.4 \\
& Overweight & 24 & 28.9 \\
Medications Adherence & Obese & 28 & 33.7 \\
Duration Of Disease & Mean \pm Sd & $27.1 \pm 6.2$ & \\
& Yes & 41 & 49.4 \\
Family History For Asthma & No & 42 & 50.6 \\
& $1<5$ Years & 10 & 12.0 \\
Other Chronic Diseases & $5-10$ Years & 23 & 27.8 \\
Total & $>10$ Years & 50 & 60.2 \\
& No & 57 & 68.7 \\
& Yes & 26 & 31.3 \\
& No & 47 & 56.6 \\
& Yes & 36 & 43.4 \\
& & 83 & 100 \\
& & &
\end{tabular}




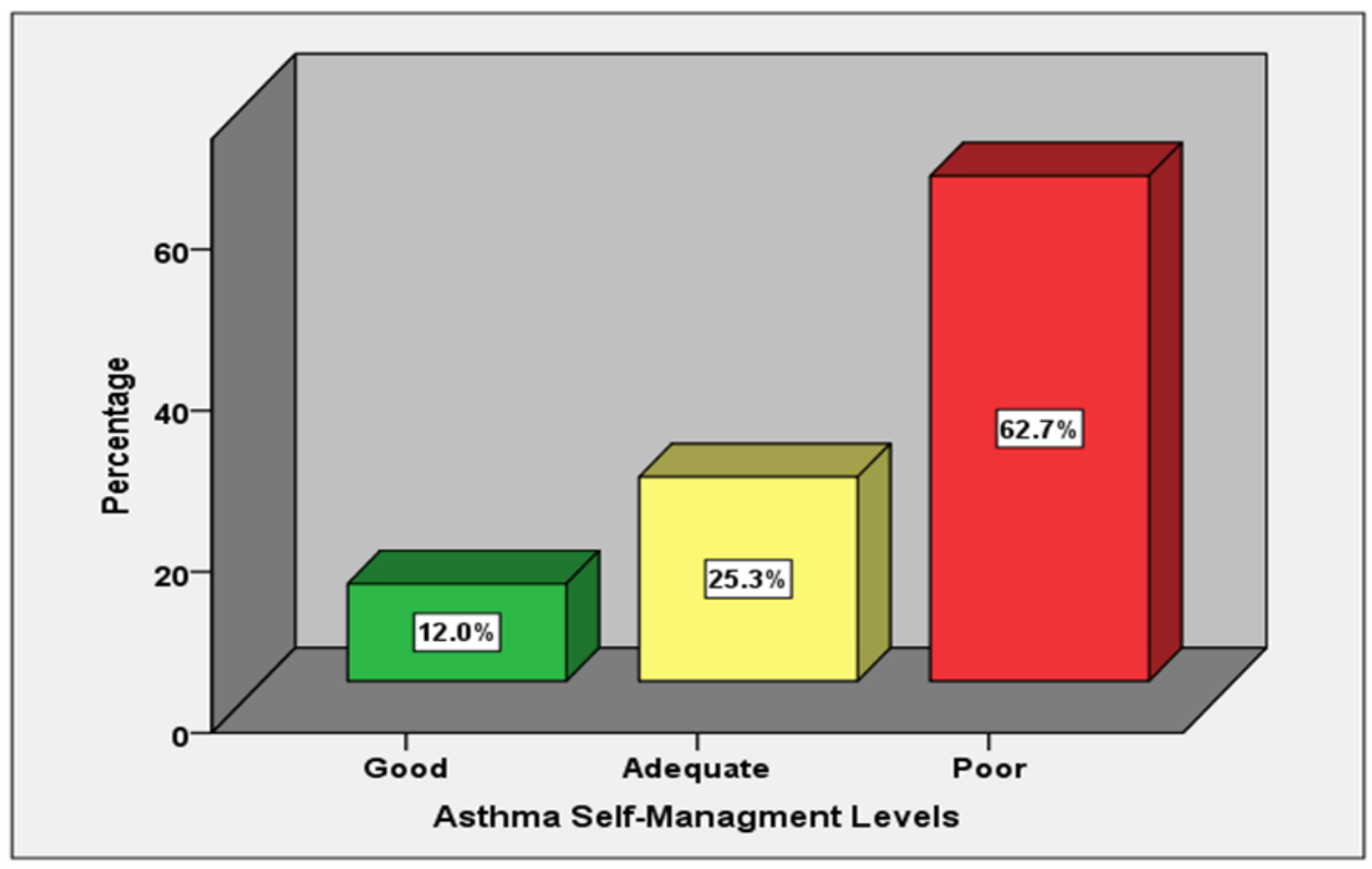

Figure (1) Self-management level

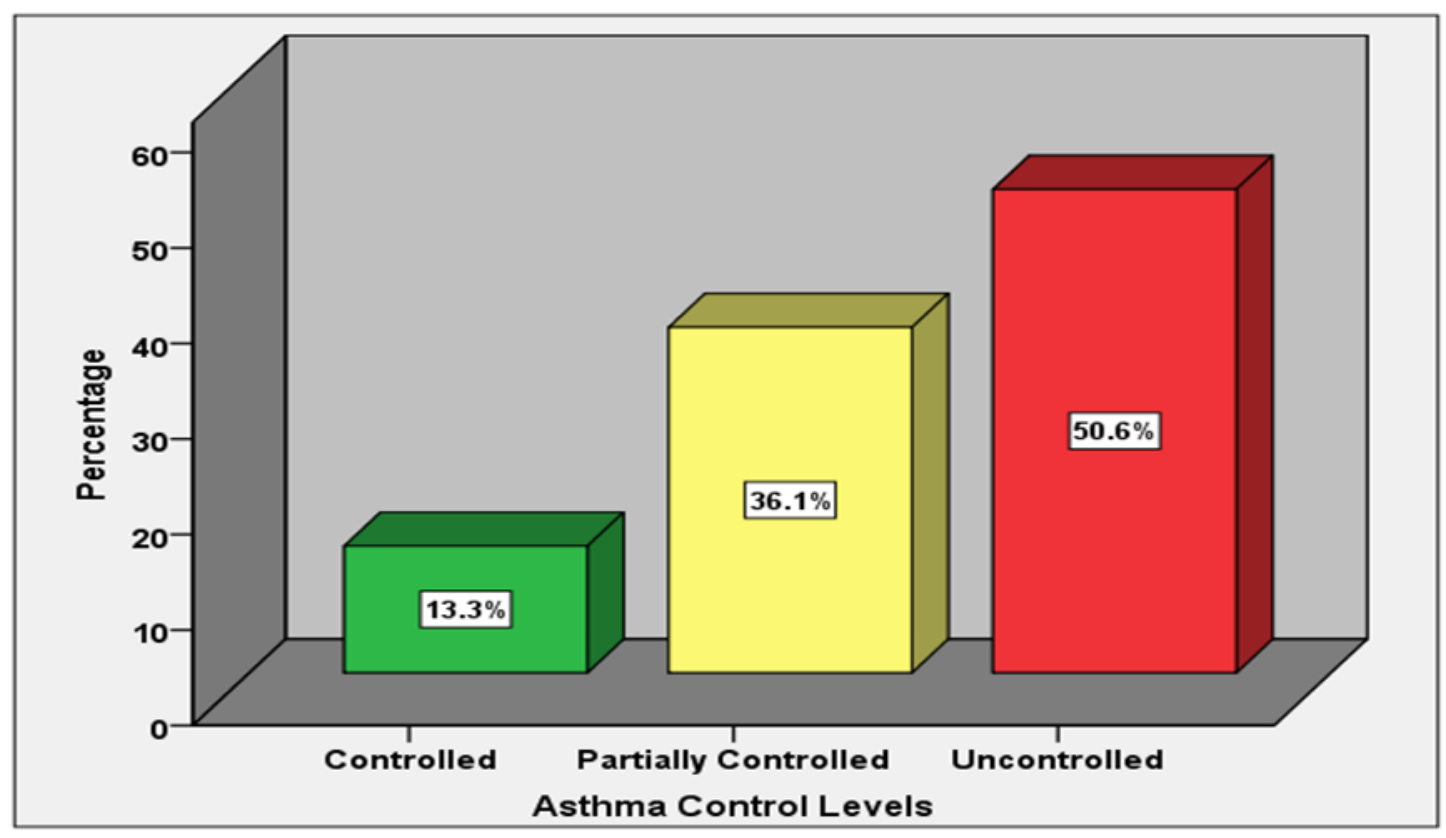

Figure (2) the level of Asthma Control 
Table (3) Association between Asthma self-management knowledge and levels of asthma control Asthma Control Levels Asthma Self-Management Knowledge

\begin{tabular}{l|lllll}
\hline \multirow{3}{*}{ Controlled } & & Good & Adequate & Poor & Total \\
& No & 5 & 5 & 1 & 11 \\
Partially Controlled & $\%$ & 50.0 & 23.8 & 1.9 & 13.3 \\
& No & 3 & 7 & 20 & 30 \\
Uncontrolled & $\%$ & 30 & 33.3 & 38.5 & 36.1 \\
& No & 2 & 9 & 31 & 42 \\
Total & $\%$ & 20 & 42.9 & 59.6 & 50.6 \\
& No & 10 & 21 & 52 & 83 \\
Fisher's Exact Test: 20.153 & $\%$ & 100 & 100 & 100 & 100 \\
& & & P: 0.0001 & High Significant
\end{tabular}

